\title{
Sexual behaviour in ovariectomized cows treated with oestradiol benzoate and testosterone propionate
}

\author{
G. K. Nessan and G. J. King \\ Department of Animal and Poultry Science, University of Guelph, Guelph, Ontario, \\ Canada NIG 2 WI
}

\begin{abstract}
Summary. Sexual behaviour was not induced in ovariectomized cows by single doses of 100 or $250 \mu \mathrm{g}$ oestradiol benzoate or by 3 injections of $50 \mu \mathrm{g}$ oestradiol benzoate given at 12 -h intervals. Treatment with 3 doses of 250 or $500 \mu \mathrm{g}$ oestradiol benzoate at 12 -h intervals produced plasma levels that were similar to those during pro-oestrus and oestrus in intact cows, and 11 of 12 treated animals showed oestrous behaviour. The higher dose resulted in a more pronounced response in 'mounting' and 'mounted' behaviour and a shorter interval to the onset of behavioural signs of oestrus. Oestrous behaviour was not observed in any ovariectomized cows treated with 1,2 or $20 \mathrm{mg}$ testosterone propionate, doses that resulted in plasma levels comparable to those in intact pro-oestrous animals. Treatment with pharmacological doses of testosterone propionate resulted in transient mounting and interest in similarly treated females, but the results were inconsistent.
\end{abstract}

\section{Introduction}

Previous reports have indicated that oestrogen injections may produce oestrous behaviour in ovariectomized cows but the results have been inconsistent (Asdell, De Alba \& Roberts, 1945; Melampy, Emmerson, Rakes, Hanka \& Eness, 1957; Melampy \& Rakes, 1958; Ray, 1965; Hobson \& Hansel, 1972; Short, Howland, Randle, Christensen \& Bellows, 1973; Nancarrow \& Radford, 1976). Some of the differences observed might be due to the various doses of oestrogen administered, the duration of administration, the injection vehicle, or synergism with other hormones. An elevation in plasma testosterone occurs in cows before oestrus and it has been suggested that the combination of oestrogen and testosterone may be necessary for the full manifestation of oestrous behaviour (Shemesh \& Hansel, 1974; Kanchev, Dobson, Ward \& Fitzpatrick, 1976). The present experiments were therefore designed to investigate the role of oestrogen and testosterone, administered in dosages expected to produce physiological blood levels, on the induction of sexual behaviour in ovariectomized dairy cows.

\section{Materials and Methods}

Experimental animals and general procedures

Six apparently normal Holstein-Friesian cows with regular oestrous cycles of 21 days, housed in tie stalls and milked in an adjacent parlour each morning and evening, were selected for daily blood sampling throughout one complete oestrous cycle during their $3 \mathrm{rd}$ month of lactation. These cows were considered to be in oestrus on the day that they passively accepted mounting by herdmates during periods when they were loose, awaiting entry into the milking 
parlour. Commencing on the day of oestrus, $20 \mathrm{ml}$ blood were collected from the coccygeal vein into heparinized tubes. The blood was centrifuged and the plasma was stored at $-20^{\circ} \mathrm{C}$ until assayed for oestrogen and testosterone.

Eleven additional cows, aged 4-11 years and scheduled for culling from the University research herd for reasons other than reproductive failure, were obtained after lactation had ended. These cows were housed in a windowless, free-stall area with a slotted floor and comfort stalls. The animals were bilaterally ovariectomized by the flank or vaginal route and a recovery period of 3 weeks was allowed before any experimental treatment. Blood samples were collected from all the ovariectomized cows before any steroid treatment.

The steroids were given as intramuscular injections to each of 3 ovariectomized cows at the same time. Oestradiol benzoate and testosterone propionate (Sigma, St Louis, Missouri) were dissolved in absolute ethanol. Further dilutions of the stock solutions were made in distilled water just before injection to give the required concentrations of steroid in a final volume of $2 \mathrm{ml}$. The injected volume of the highest dose for each steroid contained $20 \%$ ethanol and the percentage was proportionally reduced as the dosages decreased. All other animals were injected with the vehicle only to serve as controls. A teflon catheter (Becton Dickenson 'Longdwel', 18 gauge $\times 28 \mathrm{~cm}$ ) was placed in the jugular vein of one or more animals in each treatment group on the day before injection. Blood samples were subsequently collected into heparinized tubes, as indicated in Exps I and II, to monitor oestrogen or testosterone concentrations in plasma.

The behaviour of the ovariectomized cows was observed continuously for $96 \mathrm{~h}$ after each steroid treatment by a closed circuit television system and a time-lapse videorecorder (Hurnik, King \& Robertson, 1975; King, Hurnik \& Robertson, 1976). Behavioural information was collected by daily reviewing of videotapes. All cows were marked laterally and dorsally with identifying numbers to ensure positive identifications. Sexual behaviour was classified into the 'mounting period' when the animal was attempting to mount herd-mates but would not stand herself, and the 'mounted period' when the cow passively accepted mounting.

\section{Experiment I}

Each of 3 ovariectomized cows received a single injection of $50 \mu \mathrm{g}$ oestradiol benzoate, 100 $\mu \mathrm{g}$ oestradiol benzoate, $250 \mu \mathrm{g}$ oestradiol benzoate, $2 \mathrm{mg}$ testosterone propionate or $20 \mathrm{mg}$ testosterone propionate. All treated cows were cannulated for collection of blood at $-24,-0.5 \mathrm{~h}$ and immediately before treatment. Samples after injection were taken at 15 -min intervals for the first hour; every hour for the next $5 \mathrm{~h}$; at 3 -h intervals until $27 \mathrm{~h}$ and subsequently at 39,51 and $75 \mathrm{~h}$.

\section{Experiment II}

Three ovariectomized cows each received 3 injections of $50,100,250$ or $500 \mu$ g oestradiol benzoate (Groups OB) or 1, 2 or $20 \mathrm{mg}$ testosterone propionate (Groups TP) at 12-h intervals. The treatments with 250 and $500 \mu \mathrm{g}$ oestradiol benzoate and the $20 \mathrm{mg}$ testosterone propionate were replicated once to give a total of 6 cows in each of these groups. The second replicates for Groups OB-500 and TP-20 were given at the same time. One or two animals in each treatment group were cannulated on the day before the first injection. Blood samples were collected $24 \mathrm{~h}$ before treatment started, at the time of each injection and every hour for $5 \mathrm{~h}$ after each injection. Frequent samples were only taken for $5 \mathrm{~h}$ to give the animals an uninterrupted period in which sexual behaviour could be demonstrated. Collections were also made at 24 and $48 \mathrm{~h}$ after the third injection. 


\section{Experiment $I I I$}

Each of 3 ovariectomized cows received one of the following treatments: $50 \mathrm{mg}$ testosterone propionate $+100 \mu \mathrm{g}$ oestradiol benzoate $12 \mathrm{~h}$ later; $50 \mathrm{mg}$ testosterone propionate $+250 \mu \mathrm{g}$ oestradiol benzoate $12 \mathrm{~h}$ later; 3 injections of $2 \mathrm{mg}$ testosterone propionate at 12 -h intervals + $100 \mu \mathrm{g}$ oestradiol benzoate $12 \mathrm{~h}$ later. No blood samples were collected in this experiment.

The minimum duration between individual treatments was 7 days and individual cows were allowed at least 14 days between steroid injections. With the exception of one trial described in Exp. II, when 3 animals were treated with oestradiol benzoate and 3 with testosterone propionate at the same time, only one treatment was tested each week.

\section{Hormone analyses}

Plasma oestrogen and testosterone concentrations were measured by radioimmunoassay as previously described by Erb, Monk, Mollett, Malven \& Callahan (1976) or Croze \& Etches (1980). The testosterone antibody (Croze \& Etches, 1980) did not cross-react with any androgens previously reported to be present in bovine plasma with the exception of $5 \alpha$-dihydrotestosterone $(61.5 \%)$, but the antiserum raised against oestradiol-17 $\beta$ had a $50 \%$ cross-reactivity with oestradiol-17 $\alpha$ and oestrone (Erb et al., 1976). Assay results are therefore reported as testosterone and oestrogen. Mean extraction recoveries and blank values were $82 \pm$ $2.4 \%$ and $2.5 \pm 0.36 \mathrm{pg} / \mathrm{ml}$ for the oestrogen assay, and $86.5 \pm 1.4 \%$ and $2.5 \pm 0.35 \mathrm{pg} / \mathrm{ml}$ for the testosterone assay. Displacement curves for each of the steroids with various volumes of plasma were parallel to their corresponding standard curves. Between- and within-assay coefficients of variation were 14.0 and $4.3 \%$ for oestrogen, and 5.1 and $3.7 \%$ for testosterone. The sensitivities were $6 \mathrm{pg}$ for oestrogen and $15 \mathrm{pg}$ for testosterone.

Whenever variance is indicated it represents the standard error of the mean.

\section{Results}

An oestrogen level of $27.3 \pm 2.1 \mathrm{pg} / \mathrm{ml}$ was observed on the day that the intact cows demonstrated oestrous behaviour. Daily values then declined to around $20 \mathrm{pg} / \mathrm{ml}$ with the lowest level $(15.6 \pm 1.8 \mathrm{pg} / \mathrm{ml})$ recorded on Day 14 . The oestrogen levels then increased with peaks of $37 \pm 10.3$ on Day 17 and $35.1 \pm 2.2$ on Day 20 . Testosterone fluctuated between 27.5 and 44 $\mathrm{pg} / \mathrm{ml}$ through most of dioestrus with peaks of $60.8 \pm 9.0$ on Day 11 and $72.1 \pm 4.2$ on Day 20 . The testosterone content of plasma on the day of oestrus was $46 \cdot 4 \pm 4 \cdot 2 \mathrm{pg} / \mathrm{ml}$.

The mean concentrations of steroids in the plasma samples collected from the ovariectomized cows approximately 2 weeks after surgery were $13 \pm 1.8 \mathrm{pg}$ oestrogen $/ \mathrm{ml}$ and $22.4 \pm$ $1.3 \mathrm{pg}$ testosterone $/ \mathrm{ml}$. These means were lower than any daily values recorded during the oestrous cycle.

\section{Experiment I}

The plasma oestrogen levels during the $12 \mathrm{~h}$ immediately following a single injection of 50 or $100 \mu \mathrm{g}$ oestradiol benzoate remained within a range of $10-15 \mathrm{pg} / \mathrm{ml}$. When animals were treated with a single injection of $250 \mu \mathrm{g}$, the levels increased to $21.4 \mathrm{pg} / \mathrm{ml}$ by $0.5 \mathrm{~h}$ after injection, remained between 15 and $20 \mathrm{pg} / \mathrm{ml}$ for $12 \mathrm{~h}$ and declined to the basal level by $21 \mathrm{~h}$. No sexual behaviour was observed in any of these animals.

A single injection of $2 \mathrm{mg}$ testosterone propionate resulted in a dramatic increase in plasma testosterone to $63 \mathrm{pg} / \mathrm{ml}$ by $0.5 \mathrm{~h}$ and maximum levels of $80 \mathrm{pg} / \mathrm{ml}$ were observed at 2 and $3 \mathrm{~h}$ after injection. Plasma levels subsequently declined and returned by $12 \mathrm{~h}$ to values found in untreated, ovariectomized females. The administration of $20 \mathrm{mg}$ testosterone propionate 
produced plasma levels above $100 \mathrm{pg} / \mathrm{ml}$ after $0.5 \mathrm{~h}$ and a maximum value of $327 \mathrm{pg} / \mathrm{ml}$ at 1.25 h. Concentrations remained above $200 \mathrm{pg} / \mathrm{ml}$ until $12 \mathrm{~h}$, were still elevated $(60 \mathrm{pg} / \mathrm{ml})$ at $39 \mathrm{~h}$ but were at the preinjection level by $75 \mathrm{~h}$. Again, no sexual behaviour was demonstrated by the treated animals or herd-mates.

\section{Experiment II: treatments with oestradiol benzoate}

Scheduled bleedings were occasionally omitted if the animal appeared interested in other cows.

Group $O B-50$. There were no obvious changes in the plasma oestrogen levels after the first and second injections (Text-fig. 1). A gradual increase was noted at the first hour after the 3rd injection and a peak of $18.5 \mathrm{pg} / \mathrm{ml}$ was reached during the 2 nd hour. The levels were still elevated $(14-15 \mathrm{pg} / \mathrm{ml})$ at the 5 th hour.

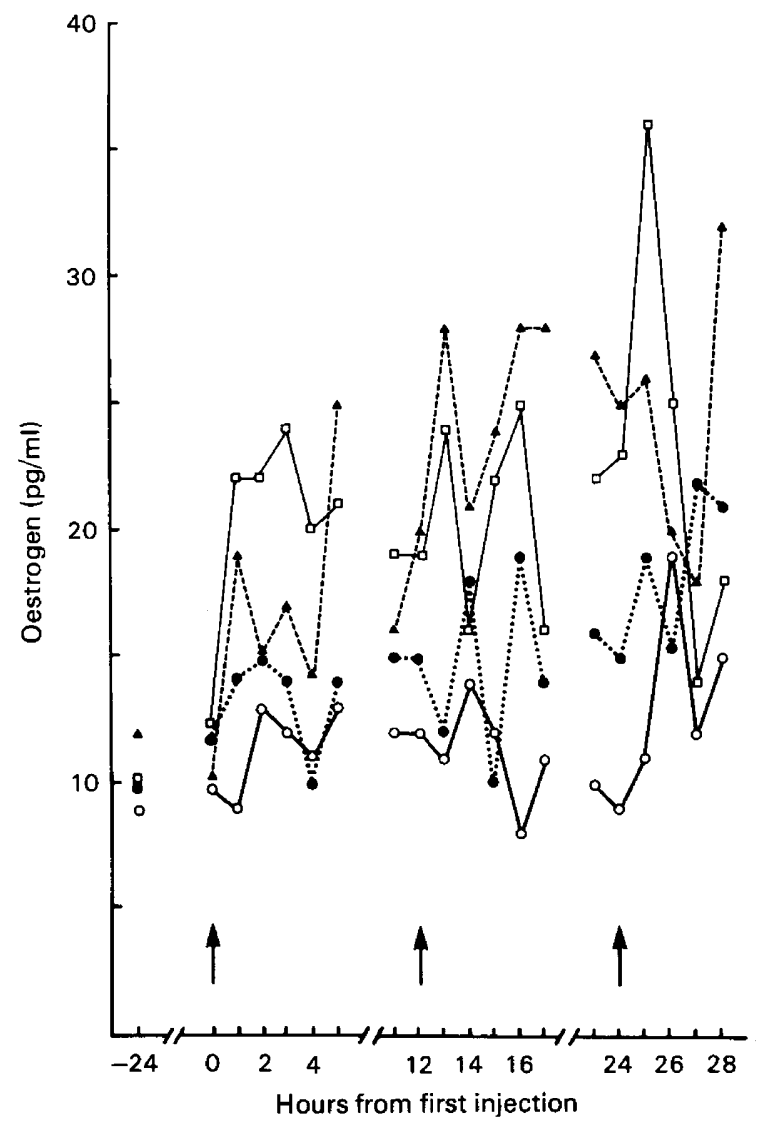

Text-fig. 1. Plasma concentrations of oestrogen in ovariectomized cows before and after treatment with 3 injections of $50 \mu \mathrm{g}(\mathrm{O}), 100 \mu \mathrm{g}(\mathbf{C}), 250 \mu \mathrm{g}(\mathbf{\Delta})$ or $500 \mu \mathrm{g}(\square)$ oestradiol benzoate at 12 -h intervals. Arrows indicate time of first, second and third injections. Each point represents the mean from 2-4 animals (see text).

Group OB-100. The changes in the plasma oestrogen were more evident with this dose (Text-fig. 1). After the first injection slight elevations were present during the first $5 \mathrm{~h}$. After the second injection there was an irregular pattern with some peaks approaching $18 \mathrm{pg} / \mathrm{ml}$, but the $3 \mathrm{rd}$ injection induced an elevation to $20-22 \mathrm{pg} / \mathrm{ml}$. 
Group $O B-250$. Approximately the same pattern, but with higher concentrations, was observed (Text-fig. 1). The first injection resulted in elevations to $19-24 \mathrm{pg} / \mathrm{ml}$, the second injection maintained values approaching $28 \mathrm{pg} / \mathrm{ml}$, and concentrations $>30 \mathrm{pg} / \mathrm{ml}$ were observed after the third injection. Values at $24 \mathrm{~h}$ after the $3 \mathrm{rd}$ injections were $16-18 \mathrm{pg} / \mathrm{ml}$.

Group $O B-500$. A prominent peak $(29 \mathrm{pg} / \mathrm{ml})$ was obtained by $1 \mathrm{~h}$ after the first injection (Text-fig. 1) and high oestrogen levels $(18 \mathrm{pg} / \mathrm{ml})$ were maintained but there was no further increase by the 5 th hour. Concentrations after the 2 nd injection were not as high as those for cows in Group OB-250. There was a sharp increase during the first hour after the third injection $(36 \mathrm{pg} / \mathrm{ml})$ but the concentration was similar to that $(34 \mathrm{pg} / \mathrm{ml})$ obtained in Group OB-250 cows during the same period. Samples of cows in Groups OB-250 and OB-500, collected $24 \mathrm{~h}$ after the $3 \mathrm{rd}$ injection, contained $16-18 \mathrm{pg} / \mathrm{ml}$.

No sexual behaviour was observed in cows in Groups OB-50 or OB-100. All 6 cows in Group OB-500 and 5 of 6 in Group OB-250 engaged in mounting and were mounted by other cows (Table 1). Vaginal hyperaemia and mucous discharge were present after the 3rd injection in all the animals in these 2 groups. The higher dose resulted in a more pronounced response in all criteria measured.

Table 1. Behavioural observations on ovariectomized cows during the days after treatment with 3 injections of oestradiol benzoate at 12 -h intervals

\begin{tabular}{lcc}
\hline & \multicolumn{2}{c}{ Oestradiol benzoate dose } \\
\cline { 2 - 3 } & $250 \mu \mathrm{g} \times 3$ & $500 \mu \mathrm{g} \times 3$ \\
\hline No. of cows treated & 6 & 6 \\
No. of cows showing signs of oestrus & 5 & 6 \\
Time from last injection to 'mounting' (h) & $12.8 \pm 2.4$ & $6 \cdot 0 \pm 0.5$ \\
Duration of 'mounting' period (h) & $5.8 \pm 2.0$ & $11.4 \pm 1.6$ \\
Time from last injection to being 'mounted' (h) & $14.2 \pm 2.3$ & $9 \cdot 3 \pm 1 \cdot 1$ \\
Duration of 'mounted' period (h) & $4.6 \pm 1.8$ & $7.5 \pm 2.0$ \\
No. of 'mounting' attempts & $8.2 \pm 3.2$ & $19.5 \pm 5.8$ \\
No. of times 'mounted' & $12.7 \pm 6.0$ & $15.3 \pm 4.0$ \\
\hline
\end{tabular}

\section{Experiment II: treatments with testosterone propionate}

The plasma testosterone patterns observed after the injection of various doses of testosterone propionate are illustrated in Text-fig. 2. The testosterone levels were elevated within the first $2 \mathrm{~h}$ following the first injection of each dose and continued to increase, reaching maximum recorded levels at the time of, or shortly after, the third injection. Samples collected $48 \mathrm{~h}$ after the last injection showed values comparable to the preinjection levels in the animals in Group TP-1, 37.5 $\mathrm{pg} / \mathrm{ml}$ in Group TP-2 and 207 in Group TP-20.

No sexual behaviour was demonstrated by any of the cows in Group TP-1. All 3 females in Group TP-20 and 2/3 of those in Group TP-2 showed short periods of mounting activity 25-26.5 h after the 3rd injection. This response was limited to 2 or 3 attempted mounts per animal and these interactions involved other treated females only. None of the treated cows passively accepted mounting.

\section{Experiment II: simultaneous treatments with oestradiol benzoate and testosterone propionate}

The 3 cows that received 3 injections of $500 \mu \mathrm{g}$ oestradiol benzoate demonstrated oestrous behaviour and attempted to mount 2 of the 3 testosterone propionate-treated $(20 \mathrm{mg} \times 3)$ females, but the latter would not stand and showed no inclination to mount. 


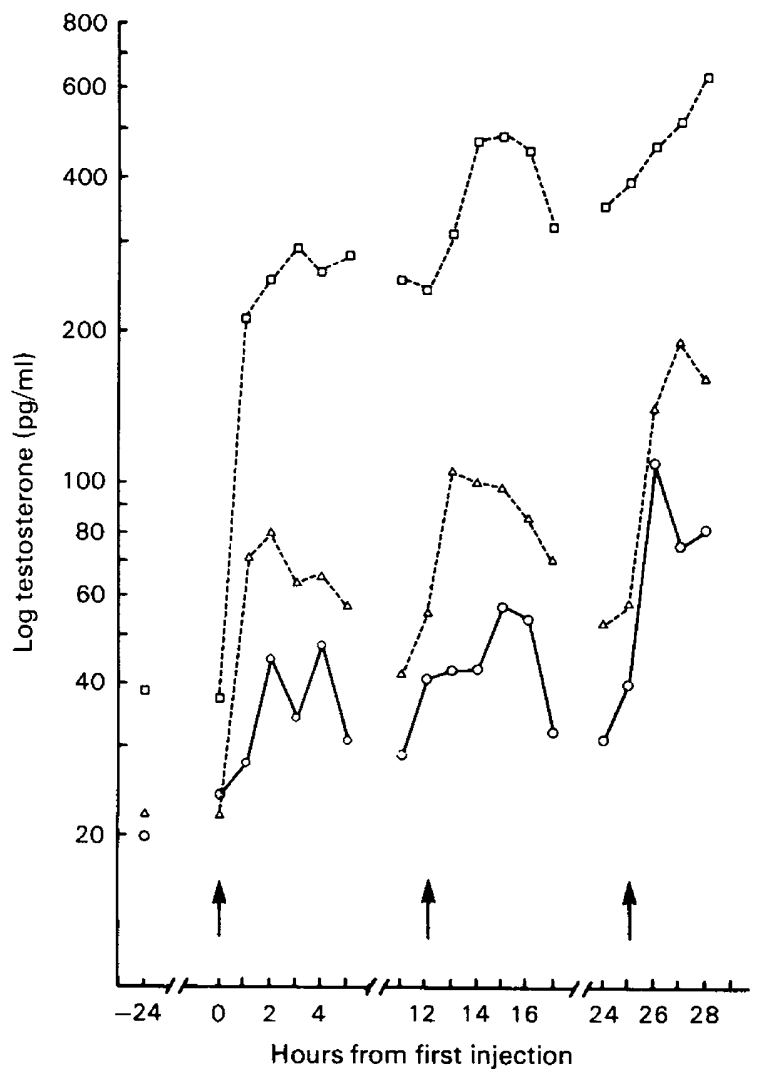

Text-fig. 2. Plasma concentrations of testosterone in ovariectomized cows before and after treatment with 3 injections of $1 \mathrm{mg}(0), 2 \mathrm{mg}(\Delta)$ or $20 \mathrm{mg}(\square)$ testosterone propionate at 12-h intervals. Arrows indicate time of first, second and third injections. Each point represents the mean from 2-4 animals (see text).

\section{Experiment III}

No mounting or mounted behaviour was observed after any of the treatments with testosterone propionate and oestradiol benzoate.

\section{Discussion}

When oestrogen and testosterone were measured throughout the oestrous cycle, peaks were recorded on the day before oestrous behaviour was observed and levels were still elevated on the day of oestrus. The patterns observed were similar to those previously reported for oestrogen (Shemesh, Ayalon \& Lindner, 1972; Dobson \& Dean, 1974) and testosterone (Shemesh \& Hansel, 1974). Plasma oestrogen and testosterone concentrations in ovariectomized cows before any steroid treatment were considerably lower than the minimum values recorded during the oestrous cycle but consistently above blank values, indicating contribution from a non-ovarian source.

The administration of 100,250 or $500 \mu \mathrm{g}$ oestradiol benzoate to ovariectomized cows resulted in an increase in plasma oestrogen within the first few hours. However, multiple injections of 250 or $500 \mu \mathrm{g}$ were required to produce levels approaching those observed during pro-oestrus in normal cyclic cows, and these were the only doses which produced 'mounting' and 
'mounted' responses. All of the testosterone propionate treatments resulted in increased plasma testosterone values after the initial injection and 3 injections of $1 \mathrm{mg}$ at 12 -h intervals yielded plasma levels similar to those in intact cows at oestrus. Increases in the amount of steroid injected did not result in a proportional increase in plasma levels. Erb et al. (1976) reported a more rapid absorption of oestradiol- $17 \beta$ following intramuscular injection in corn oil than after subcutaneous injection in absolute ethanol. It is likely that the dilute ethanol used as the vehicle in this current study resulted in some localized inflammation and interfered with absorption. The injection of uniform concentrations at multiple sites would probably result in a better relationship between the dose and response.

No sexual behaviour was observed following a single injection of 100 or $250 \mu \mathrm{g}$ oestradiol benzoate. Melampy et al. (1957) observed oestrous behaviour in 2 cows that received a single dose of $<250 \mu \mathrm{g}$ but Ray (1965) concluded that $300 \mu \mathrm{g}$ was the minimum dose that might produce receptivity. In other single-injection trials, oestrus was induced in 6 of 12 animals treated with $500 \mu \mathrm{g}$ oestradiol propionate (Holy \& Hrivnak, 1965) and in all of 6 cows receiving $500 \mu \mathrm{g}$ oestradiol benzoate (Nancarrow \& Radford, 1976). These 2 reports indicated that 500 $\mu \mathrm{g}$ oestradiol benzoate in a single injection should produce behavioural signs in a high proportion of treated animals so this treatment was not repeated in the present study.

Three injections of 250 or $500 \mu \mathrm{g}$ oestradiol benzoate administered at 12 -h intervals resulted in 'mounting' and 'mounted' responses in almost all treated females. This observation is in general agreement with results reported in previous studies in which relatively low doses and multiple injections were employed (Asdell et al., 1945; Melampy \& Rakes, 1958; Hobson \& Hansel, 1972). However, the duration of behavioural signs and number of 'mounting' and 'mounted' interactions were less than those observed when 2 or more intact cows from the same herd passed through oestrus at the same time (Hurnik et al., 1975). This suggests that although the doses produced plasma oestrogen levels similar to those present on the day before oestrus, this alone was not capable of inducing behaviour responses of the same intensity or duration as those demonstrated by intact animals.

Testosterone treatment of ovariectomized females might produce sexual behaviour directly or be a substrate for oestrogen-mediated responses. In spayed ewes, androgen treatment results in the production of vaginal pheromones so that the animals are attractive but not receptive to males (Clarke \& Scaramuzzi, 1978). Also, Sholiton \& Werk (1969) have demonstrated that the bovine brain contains the enzyme that will aromatize testosterone. The results of Exp. II, in which some of the testosterone-treated animals were attractive and/or engaged in mounting activity, suggest that a stimulus to the nervous system and pheromone production may be occurring. However, these responses were only observed when the injected doses produced plasma levels above those of the peaks noted immediately before mounting and receptivity in intact animals and the response was not consistent. Mounting behaviour has been initiated in freemartin heifers (Green, Mogil \& Foote, 1978) and in intact cows (Signoret, 1975) with testosterone implants or injections that would have produced plasma levels above the physiological range. The absence of any detected response in Exp. III, in which pharmacological doses of testosterone propionate were combined with small amounts of oestradiol benzoate, suggests that if potentiation or synergism exists between these steroids, it is a complex relationship and may involve other factors. King et al. (1976) demonstrated that only about $50 \%$ of dairy cows exhibit detectable signs of oestrus at the first post-partum ovulation but almost all subsequent ovulations were preceded by oestrous behaviour. The number of 'mounting' and 'mounted' interactions was also lower at the first ovulation (Hurnik et al., 1975). These observations support the suggestion that progesterone is involved in sensitizing the central nervous system to the androgen and/or oestrogen stimulus which results in the expression of sexual receptivity, as previously proposed for the ewe (Robinson, 1954) and the cow (Melampy et al., 1957).

The results obtained in this study suggest several tentative conclusions. Oestradiol benzoate injections that gave plasma levels in ovariectomized cows within the range observed during 
pro-oestrus and oestrus in intact cows also produced oestrous behaviour, but the response may not be as intense or the duration of sexual activity as long as those accompanying a natural oestrus. Treatment of ovariectomized cows with testosterone propionate resulted in transient mounting and attraction in some animals but only when the injected doses produced plasma levels above those that would occur during normal pro-oestrus. Further studies incorporating progesterone withdrawal with the administration of oestrogen and/or testosterone in amounts that produce physiological plasma concentrations may assist understanding of the precise role of ovarian steroids on the induction of sexual behaviour.

This research was financed by the Ontario Ministry of Agriculture and Food.

\section{References}

Asdell, J.A., De AJba, J. \& Roberts, S.J. (1945) The levels of ovarian hormones required to induce heat and other reactions in the ovariectomized cow. $J$. Anim. Sci. 4, 277-284.

Clarke, I.J. \& Scaramuzzi, R.J. (1978) Sexual behaviour and $\mathrm{LH}$ secretion in spayed androgenized ewes after a single injection of testosterone or oestradiol-17 $\beta . J$. Reprod. Fert. 52, 313-320.

Croze, F. \& Etches, R.J. (1980) The physiological significance of androgen-induced ovulation in the hen. J. Endocr. 84, 163-171.

Dobson, H. \& Dean, P.D.G. (1974) Radioimmunoassay of oestrone, oestradiol-17 $\alpha$ and $17 \beta$ in bovine plasma during the oestrous cycle and last stages of preg nancy. $J$. Endocr. 61, 479-486.

Erb, R.E., Monk, E.L., Mollett, T.A., Malven, P.V. \& Callahan, C.J. (1976) Estrogen, progesterone, prolactin and other changes associated with bovine lactation induced with estradiol-17及 and progesterone. J. Anim. Sci. 42, 644-654.

Green, W.A., Mogil, L. \& Foote, R.H. (1978) Behavioral characteristics of freemartins administered estradiol, estrone, testosterone and dihydrotestosterone. Horm. \& Behav. 10,71-84.

Hobson, W.C. \& Hansel, W. (1972) Plasma LH levels after ovariectomy, corpus luteum removal and estradiol administration in cattle. Endocrinology 91, $185-190$.

Holy, L. \& Hrivnak, J. (1965) Influences of low doses of oestrogen on libido, vaginal cell picture and crystallization pattern in cervical mucus of spayed cows. Vet. Med., Praha 10, 119-126.

Hurnik, J.F., King, G.J. \& Robertson, H.A. (1975) Estrus and related behavior in postpartum Holstein cows. Appl. Anim. Ethol. 2, 55-68.

Kanchev, L.N., Dobson, H., Ward, W.R. \& Fitzpatrick, R.J. (1976) Concentration of steroids in bovine peripheral plasma during the oestrous cycle and the effect of betamethazone treatment. J. Reprod. Fert. 48, 341-345.
King, G.J., Hurnik, J.F. \& Robertson, H.A. (1976) Ovarian activity and estrus in dairy cows during early lactation. J. Anim. Sci. 42, 688-692.

Melampy, R.M. \& Rakes, J.M. (1958) Induced estrus in ovariectomized cows. Iowa St. Coll. J. Sci. 33, 85-90.

Melampy, R.M., Emmerson, M.A., Rakes, J.M., Hanka, L.A. \& Eness, P.G. (1957) The effect of progesterone on the estrous response of estrogen conditioned ovariectomized cows. J. Anim. Sci. 16, 967-975.

Nancarrow, C.D. \& Radford, H.M. (1976) Response in ovariectomized cows to repeated injections of thyrotrophin releasing hormone (TRH) and to estradiol benzoate (OBD). Theriogenology 6, 642, Abstr.

Ray, D.E. (1965) Oestrous response of ovariectomized beef heifers to oestradiol benzoate and human chorionic gonadotrophin. J. Reprod. Fert. 10, 329335.

Robinson, T.J. (1954) The necessity for progesterone with estrogen for the induction of recurrent estrus in the ovariectomized ewe. Endocrinology 55, 403-408.

Shemesh, M. \& Hansel, W. (1974) Measurement of bovine plasma testosterone by radioimmunoassay (RIA) and by rapid competitive protein binding (CPB) assay. J. Anim. Sci. 39, 720-724.

Shemesh, M., Ayalon, N. \& Lindner, H.R. (1972) Oestradiol levels in the peripheral blood of cows during the oestrous cycle. J. Endocr. 55, 72-78.

Sholiton, J.L. \& Werk, E.E. (1969) The less polar metabolites produced by incubation of testosterone$4^{-14} \mathrm{C}$ with rat and bovine brain. Acta endocr., Copenh. 61, 641-648.

Short, R.E., Howland, B.E., Randle, R.D., Christensen, D.S. \& Bellows, R.A. (1973) Induced LH release in spayed cows. J. Anim. Sci. 37, 551-557.

Signoret, J.P. (1975) Nouvelle methode de detection de l'oestrus chez lez bovins. Annls Zootech. 24, 125127. 